\title{
Brain Musics: History, Precedents, and Commentary on Whalley, Mavros and Furniss
}

\author{
MIGUEL ORTIZ[1] \\ Goldsmiths, University of London \\ MICK GRIERSON \\ Goldsmiths, University of London \\ ATAU TANAKA \\ Goldsmiths, University of London
}

\begin{abstract}
Whalley, Mavros and Furniss explore questions of agency, control and interaction, as well as the embodied nature of musical performance in relation to the use of human-computer interaction through the work Clasp Together (beta) for small ensemble and live electronics. The underlying concept of the piece focuses on direct mapping of a human neural network (embodied by a performer within the ensemble) to an artificial neural network running on a computer. With our commentary, we contextualize the work within the field of Music Neuroscience. Specifically, we point at precedents in EEG-based musical practice as well as ongoing research in the field. We hope to more clearly situate Clasp Together (beta) in the broad area of Brain Computer Musical Interfaces and discuss the challenges and opportunities that these technologies offer for composers.
\end{abstract}

Submitted 2014 November 4; accepted 2014 December 23.

KEYWORDS: EEG, composition, cognition, live electronics, performance.

WHALLEY, Mavros, and Furniss describe a musical composition where one performer's brainwaves are tracked. The article documents the process of composing a new piece including realtime measurement and sonification of brain activity. For this composition, Whalley makes use of the Neurogranular Sampler (NGS), developed by Eduardo Miranda and John Matthias (Miranda \& Matthias, 2009). The documentation makes it easy to follow the process of this particular piece coming to fruition from a concept to a specific implementation and performance. As a piece of research, it is rigorous in the sense that it is easy and transparent to follow the steps involved in the development of the piece, which can help enable artists to avoid the issues identified by the authors and come up with solutions that better adapt to their own artistic purposes.

The work however, does not pose a significant advance in the broad field of Brain Computer Musical Interfaces (BCMIs). A look at Whalley's list of works reveals that Clasp Together (beta) is his first and (as of the publication date of this commentary) only composition that utilizes EEG signals (Whalley, 2014). This gives context to the initial struggles, assumptions, and solutions documented in the original article, but one that risks to be repeated by others if not placed in the context of the history of biosignals in the arts.

\section{BRAINWAVES AND THE ARTS}

The Electroencephalogram (EEG) monitors the electrical activity caused by the firing of cortical neurons across the brain's surface. To contextualize the work by Whalley et al., we will first give an account of the relationship between the science of brain wave monitoring and its relationship to artistic endeavors, from a historical perspective:

"Perhaps within the next hundred years, science will perfect a process of thought transference from composer to listener. The composer will sit alone on the concert stage and merely think his idealized conception of his music. Instead of recordings of actual music sound, recordings will carry the brainwaves of the composer directly to the mind of the listener." (Scott, 1949. Cited in Harper, Doughty \& Eisentraut, 2009, p.122) 
The desire for direct brain access to musical (and other artistic) content through a medium that overrides the manual translation of ideas has been described and conceptualized by artists over time. Even before Scott's projection that such a device would one day become possible through the aid of computers, in 1919 German poet Rainer Maria Rilke wrote an essay entitled Primal Sound, in which he pointed out the similarities between the shape of the coronal suture of human skulls and the grooves carved in early phonograph wax cylinders. In the author's own words:

"The coronal suture of the skull has - let us assume - a certain similarity to the closely wavy line which the needle of a phonograph engraves on the receiving, rotating cylinder of the apparatus. What if one changed the needle and directed it on its return journey along translation of a sound, but existed of itself naturally - well, to put it plainly, along the coronal suture, for example. What would happen? A sound would necessarily result, a series of sounds, music.... Feelings - which? Incredulity, timidity, fear, awe - which of all the feelings here possible prevents me from suggesting a name for the primal sound which would then make its appearance in the world..." (Rilke, 1978)

The poetic image painted by Rilke is captivating, yet for the contemporary reader it is easy to question the meaningful relationship between the characteristics of the coronal suture of the skull and their link to feelings and music. In a similar way, Scott's projections are not currently achievable, in the sense that an imagined sound or compositional work can not currently be rendered entirely based on the analysis of brain activity without mapping strategies and/or additional interventions that breach the path of direct composer-listener interaction.

Technology has now advanced to a point where there has been significant progress in the field of Brain Computer Interfaces that are beginning to make possible the translation of subjective states to information that can be used for the real-time control of musical devices. Novel signal analysis methods and the proliferation of accessible and affordable consumer devices bring this ideal closer to artistic practitioners, yet we remain at a state where the direct rendering of a fully formed composition by brain interaction alone is not yet feasible. This current limitation has led artists and researchers to employ a myriad of approaches when creating works that use the EEG for musical activity.

\section{MUSICAL PRECEDENTS}

Composers' interest in the potential of brain music has a rich and long history, dating back a half century. Alvin Lucier's pioneering work with alpha waves in his 1964 piece Music for Solo Performer (Holmes, 2002) is largely considered the first composition to effectively use EEG signals. Richard Teitelbaum and David Rosenboom also explored biofeedback in the 1960s, resulting in Rosenboom's (now Dean of Music at the California Institute for the Arts) seminal book, Biofeedback and the Arts, Results of Early Experiments (Rosenboom, 1976). In the digital era, Knapp and Lusted created musical instruments that exploited the EEG (Knapp \& Lusted, 1988, 1996; Lusted \& Knapp, 1990; Sobolewski, O’Mullane, Knapp, \& Reilly, 2007). Miranda, whose Neurogranular Sampler (NGS) platform was used in Clasp Together (beta), has a large body of musical work using EEG over the last ten years. This history is documented in a special edition of the CEC's eContact! Journal, Biotechnological Performance Practice (Brouse, 2012; Ortiz, 2012).

Music Neuroscience is a large field of research which encompasses different goals such as: understanding more about the brain using music as a case study, understanding more about the human activity of music making, music perception, the role of memory in music performance, brain plasticity in learning to play a musical instrument, and the way in which musical training can aid in the acquisition of language and cognitive skills (Rosenboom, 2014). Such diverse areas of inquiry continue to expand the possibilities of the use of EEG signals for artistic purposes.

In our work, for example, we rely on the use of P300 Event Related Potentials (ERPs) generalizable brain signals that signify the moment when an event emerges in the consciousness of individuals (for recent work in this area see Bowman, Filetti, Alsufyani, Janssen, \& Su, 2014; Spencer, 2005). As these signals are thought to represent an act of cognition, they reveal internal subjective states of attention, bringing to the surface the materiality of cognitive processes, and as such, this has political and sociological meaning in that the materiality of conscious thought is foregrounded (Grierson, Kiefer, \& Yee-King, 2011; Grierson \& Kiefer, 2011; Grierson, 2008).

A strong plea is made for the humanitarian application of biological feedback technology. It is in this context that Rosenboom put forth a call for artists and socially concerned scientists to pursue the study of biofeedback as a means of opening up "the astounding ability to consciously experience and 
bring under self-control many of the hitherto unconscious neural processes on which mental life is founded.” (Blum, 1989, p. 86)

\section{BRAIN INTERFACES TODAY}

Clasp Together (Beta) falls into the area of research that focuses on the establishment of Brain Computer Music Interfaces (BCMIs) for real-time music performance practice, where data monitored from the human Electroencephalogram (EEG) is used in real-time to control musical processes.

The technical implementation of the piece calls for the Emotiv EPOC EEG headset, an affordable consumer device for EEG measurement. The authors give an account of the advantages of using this particular platform, namely: its affordability, portability, wireless connection and relative ease of use as opposed to the intricate wiring of a traditional EEG system. This is an important consideration as traditional EEG systems from the medical field are not well suited for stage performance, requiring the participation of trained EEG researchers. The authors also provide two accounts of related EEG-driven artistic works: Neuro-Knitting (Guljajeva, Canet, \& Mealla, 2013) and Brain Music (Paile, 2011). These works are good examples of recent explorations that make specific use of the Emotiv EPOC in artistic contexts but are not representative of the state of the art research in BCMIs. As such, the article does not broach the research field of BCMI but instead describes the practical applications and challenges posed by the use of a specific device, within the compositional context of a specific work. The article thus presents documentation of an evocative use of a consumer brain-computer interface in contemporary musical practice.

The authors employed the pre-defined states as categorized by the Expressiv Suite software provided with the EPOC headset. Because this is a proprietary "black box", there is no indication of the actual EEG analysis algorithms used (Lang, 2012). Several strategies have been employed to communicate to the audience when a musical event is being controlled by the EEG signal in contrast to fully notated musical passages and random or autonomous events generated by the NGS, although, how the acknowledgment of these events by the audience relates to the compositional ideas is not covered in detail.

\section{CONCLUSION}

The advent of affordable devices is allowing for the artistic exploration of EEG signals by a larger community of practitioners. Yet, EEG analysis methodology does not have a current presence on the musical composition curriculum at universities. Composers are not and cannot be expected to know about the latest developments in this field. This outlines the need for more generalized devices and analysis algorithms available for the artistic community at large and its proper documentation. Due to the complex nature of the field there is the need for a bridge that conveys the knowledge gathered by the dedicated researchers working on BCMIs and the wider interactive arts community (for recent work on this area see Grierson \& Kiefer (2014) and Miranda \& Castet (2014).

Our commentary is on the published research paper and not on the musical work. In between the two come technique (both musical and scientific) and method allowing composers and researchers alike to benefit from this fascinating field's long history. We respect the composer's decisions in an artistic context and admire the ambition that led to Clasp Together (beta). The article provides a good account of the ideas, concepts and practical steps on the composition of a musical work. As such, the reader is able to follow the challenges of dealing with novel technologies in artistic decision-making. It provides valuable information for artists interested in using real-time EEG monitoring for musical composition and performance.

Our commentary outlines current developments in BCI research and hope they will be of interest to the wider musical research community. EEG monitoring in real-time for artistic purposes is an increasingly active area of research, one whose potential is only limited by our current analysis algorithms and the relationship between their results and the artistic uses that composers can imagine.

\section{NOTES}

[1] Correspondence can be addressed to: Dr. Miguel Ortiz, Goldsmiths, University of London. m.ortiz@gold.ac.uk 


\section{REFERENCES}

Blum, T. (1989). Biofeedback and the Arts: Results of early experiments. Computer Music Journal, 13(4), 86-88.

Bowman, H., Filetti, M., Alsufyani, A., Janssen, D., \& Su, L. (2014). Countering countermeasures: Detecting identity lies by detecting conscious breakthrough. PloS One, 9(3).

Brouse, A. (2012). A young person's guide to brainwave music: Forty years of audio from the human EEG. eContact!, 14(2).

Grierson, M. (2008). Composing with brainwaves: Minimal trial P300b recognition as an indication of subjective preference for the control of a musical instrument. In Proceedings of the International Computer Music Conference. Belfast, Northern Ireland.

Grierson, M., \& Kiefer, C. (2011). Better brain interfacing for the masses: Progress in event-related potential detection using commercial brain computer interfaces. In CHI'11 Extended Abstracts on Human Factors in Computing Systems (pp. 1681-1686). New York: ACM.

Grierson, M., \& Kiefer, C. (2014). Contemporary approaches to music BCI using P300 event related potentials. In E. R. Miranda \& J. Castet (Eds.), Guide to brain-computer music interfacing (pp. 43-59). London: Springer.

Grierson, M., Kiefer, C., \& Yee-King, M. (2011). Progress report on the EAVI BCI toolkit for music: Musical applications of algorithms for use with consumer brain computer interfaces. In Proceedings of the International Computer Music Conference, 2011 (pp.110-113). Huddersfield, UK.

Grierson, M. (2011). Progress report on the EAVI BCI toolkit for music: musical applications of algorithms for use with consumer brain computer interfaces. Ann Arbor, MI: MPublishing, University of Michigan Library.

Guljajeva, V., Canet, M., \& Mealla, S. (2013). NeuroKnitting. Retrieved from http://www.varvarag.info/neuroknitting/

Harper, G., Doughty, R. \& Eisentraut, J. (2009). Sound and music in film and visual media: A critical overview. New York: Bloomsbury.

Holmes, T. B. (2002). Electronic and experimental music: Pioneers in technology and composition (2nd ed.). New York: Routledge.

Knapp, R. B., \& Lusted, H. S. (1988, April). A real-time digital signal processing system for bioelectric control of music. In Acoustics, Speech, and Signal Processing, 1988. ICASSP-88., 1988 International Conference on (pp. 2556-2557). IEEE.

Knapp, R. B., \& Lusted, H. S. (1996). Controlling computers with neural signals. Scientific American, 275(4), 82-87.

Lang, M. (2012). Investigating the Emotiv EPOC for cognitive control in limited training time (Honours report, University of Canterbury, New Zealand). Retrieved from http://citeseerx.ist.psu.edu/viewdoc/download?doi=10.1.1.304.3228\&rep=rep1\&type=pdf, 8 .

Lusted, H. S., \& Knapp, R. B. (1990). A bioelectric controller for computer music applications. Computer Music Journal, 14(1), 42-47.

Miranda, E. R., \& Castet, J. (Eds.) (2014). Guide to brain-computer music interfacing. London: Springer.

Miranda, E. R., \& Matthias, J. (2009). Music neurotechnology for sound synthesis: Sound synthesis with spiking neuronal networks. Leonardo, 42(5), 439-442. 
Ortiz, M. (2012). A brief history of biosignal-driven art: From biofeedback to biophysical performance. eContact!, 14(2).

Paile, D. (2011). Brain Music. Retrieved from https://www.youtube.com/watch?v=xYfw7QTZC4g

Rilke, R. M., \& Levertov, D. (1978). Where silence reigns: Selected prose. New Directions Publishing Corporation.

Rosenboom, D. (1976). Biofeedback and the Arts, Results of Early Experiments. Vancouver, BC, Canada: Aesthetic Research Centre of Canada, A.R.C.

Rosenboom, D. (2014). Active imaginative listening-a neuromusical critique. Frontiers in Neuroscience, $8,251$.

Scott, R. http://raymondscott.com/Liner1.html, Last accessed 08/02/2008

Sobolewski, R., O'Mullane, B., Knapp, R. B., \& Reilly, R. B. (2007). A portable neurological monitor for use in cognitive function studies. In Engineering in Medicine and Biology Society, 2007. EMBS 2007. 29th Annual International Conference of the IEEE (pp. 2940-2943). Lyon, France: IEEE.

Spencer, K. M. (2005). Averaging, detection, and classification of single-trial ERPs. In T. C. Handy (Ed.), Event-related potentials: A methods handbook, (pp. 209-228). Cambridge, MA: MIT Press.

Whalley, J. H. (2014). Classical - Harry Whalley. Retrieved from http://www.harrywhalley.com/classical/ 